УДК 316.77

DOI 10.52575/2712-746X-2021-46-4-782-784

\title{
История благотворительности в г. Белгороде как форма социально-правовой конъюнкции
}

\author{
${ }^{1}$ Кистенев В.В., ${ }^{2}$ Посохова Я.В. \\ ${ }^{1}$ Белгородский государственный институт искусств и культуры, \\ Россия, 308033, г. Белгород, ул. Королева, 7 \\ ${ }^{2}$ Московский государственный университет им. М.В. Ломоносова, \\ Россия, 119991, г. Москва, Ленинские горы, д. 1 \\ E-mail: kisvita@mail.ru; natalina_76@mail.ru
}

\begin{abstract}
Аннотация. Рассмотрены исторические аспекты социального партнерства таких общественных субъектов, как государство, религиозные и благотворительные организации. Выделен пример «вмещающей» социальной сущности - феномена благотворительности, являющейся ядром социальной конъюнкции. Показано, что в сфере общественных отношений зафиксированные «конъюнктивные эффекты» выступают как результат практик консолидации в ответ на кризисные проявления, возникающие в социуме.
\end{abstract}

Ключевые слова: город, социальные субъекты, благотворительность, социально-правовая конъюнкция.

Для цитирования: Кистенев В.В., Посохова Я.В. 2021. История благотворительности в г. Белгороде как форма социально-правовой конъюнкции. NOMOTHETIKA: Философия. Социология. Право, 46 (4): 782-784. DOI: 10.52575/2712-746X-2021-46-4-782-784

\section{The History of Charity in Belgorod as a Form of Social and Legal Conjunction}

\author{
${ }^{1}$ Vitaliy V. Kistenev, ${ }^{2}$ Yana V. Posohova \\ ${ }^{1}$ Belgorod State Institute of Arts and Culture, \\ 7 Koroleva St, Belgorod 308033, Russian Federation \\ ${ }^{2}$ Lomonosov Moscow State University \\ 1 Leninskie Gory St, Moscow 119991, Russian Federation \\ E-mail: kisvita@mail.ru; natalina_76@mail.ru
}

\begin{abstract}
The historical aspects of social partnership of such public entities as the state, religious and charitable organizations are considered. An example of the "enclosing" social essence is highlighted - the phenomenon of charity, which is the core of the social conjunction. It is shown that in the sphere of public relations, the recorded "conjunctive effects" appear as a result of consolidation practices in response to crisis manifestations that arise in society.
\end{abstract}

Key words: city, social subjects, charity, social and legal situation.

For citation: Kistenev V.V., Posohova Ya.V. 2020. The History of Charity in Belgorod as a Form of Social and Legal Conjunction. NOMOTHETIKA: Philosophy. Sociology. Law, 46 (4): 782-784 (in Russian). DOI: 10.52575/2712-746X-2021-46-4-782-784 
Сегодня благотворительность как социально-правовое явление приобретает новые формы, смыслы и трансформации. Из-за складывающегося общественного расслоения в России вопросы адресной помощи нуждающимся стоят в повестке дня остро и требуют не только государственного, но и негосударственного (благотворительные организации в частности) участия. Деятельность меценатов, некоммерческих организаций и различных фондов традиционно выступает публичным инструментом смягчения нарастающей напряженности в социуме. В свете вышесказанного актуально определение их места и роли в современной Российской действительности. Не вызывает сомнения необходимость исследования партнерства между социальными субъектами - государственными, религиозными и благотворительными организациями. Анализ накопленного исторического опыта благотворительной деятельности - нетривиальная теоретическая и практическая проблема современного научного знания.

Одним из примеров «вмещающей» социальной сущности, являющейся ядром социальной конъюнкции, на наш взгляд, является «благотворение» на Белгородчине. Следует отметить, что в рассматриваемой сфере общественных отношений зафиксированные «конъюнктивные эффекты» выступают как результат практик консолидации.

Рассматривая исторический аспект, необходимо отметить, что на Белгородской земле проявились многочисленные примеры безвозмездной помощи нуждающимся людям при монастырях и приходах Русской православной церкви. Своими трудами и подвигами прославил ее святитель Иоасаф, причисленный впоследствии к лику святых.

Государство в лице Петра I попыталось в первой четверти XVIII века систематизировать социально-правовую составляющую дела призрения, то есть придать совершенно иной статус, отдав часть функций благотворительности светским органам власти в правительстве и общественных управлениях. Петр Алексеевич сам жертвовал большие суммы на благотворительность: так, памятником пребывания царя в Белгороде стал УспенскоНиколаевский собор, на строительство которого Петр I передал сто рублей. Екатерина II осознавала благотворительность как компонент политики «просвещенного абсолютизма». В XIX веке возникает Человеколюбивое общество, целью которого являлась помощь нуждающимся в стране. Государство таким образом привлекало внимание общественности к благотворительной деятельности.

Частные благотворители оказывали помощь, финансируя проекты строительства и содержания больниц, приютов, богаделен, оказания помощи сиротам, военным и членам их семей. Так, в г. Белгороде известны фамилии Чумичевых, Юсуповых, Харитоненко, графини С.В. Паниной и других.

В качестве примера уместно привести исторические данные о благотворительной помощи белгородцев в период войны 1812 года. Так, в фонд обороны Отечества земляками было внесено порядка двенадцати тысяч рублей, а один из богатых местных помещиков Хорват пожертвовал пятьсот рублей.

Необходимо подчеркнуть, что наиболее яркие проявления благотворительной помощи возникали в российском социуме в период острых социальных кризисов: войн, массовых болезней, голода. Общество как сложная, открытая и многоуровневая система, в основе которой лежит коллективная деятельность людей, пытается компенсировать возникающие лакуны, включаются компоненты некой саморегуляции. Возможность и глубина данных явлений, с нашей точки зрения, является прямым следствием развития морально-нравственного и духовного потенциала народа. Генерируются такие конструкты, как «солидарность», «справедливость», «сочувствие», «бескорыстие», «причастность», «ответственность», «объединение».

В XXI веке феномен благотворительности насыщается новыми формами: социальные сети, сбор средств нуждающимся по телефону или посредством Интернета. Образуются точки неопределенности в методах организации общественной жизни, роли субъектобъектных социальных отношений и разработки критериев для реализации человеческих 
потребностей в обществе. Возникает необходимость интегрирования третьего сектора экономики в область социальной политики в качестве поддерживающей и стабилизирующей силы, что вызывает потребность в современной организационно-правовой основе. Происходит постоянный рост числа негосударственных некоммерческих организаций, в том числе благотворительных, что требует координации их деятельности и контроля.

Так в г. Белгороде весомая роль принадлежит организациям, которые осуществляют благотворительную деятельность в культурной, просветительской, социальноэкономической, научно-образовательной и других сферах жизни общества, опирающихся на сложившийся исторический опыт - как форму социально-правовой конъюнкции.

Конфликт интересов: о потенциальном конфликте интересов не сообщалось.

Conflict of interest: no potential conflict of interest related to this article was reported.

\section{ИНФОРМАЦИЯ ОБ АВТОРАХ}

Кистенев Виталий Валентинович, кандидат исторических наук, доцент кафедры общетеоретических и гуманитарных дисциплин Белгородского государственного института искусств и культуры, г. Белгород, Россия

Посохова Яна Витальевна, студент IV курса юридического факультета Московского государственного университета им. М.В. Ломоносова, г. Москва, Россия

\section{INFORMATION ABOUT THE AUTHORS}

Vitaliy V. Kistenev, Candidate of Historical Sciences, Associate Professor of the Department of General Theoretical and Humanitarian Disciplines of the Belgorod State Institute of Arts and Culture, Belgorod.

Yana V. Posohova, IV-year student of the Faculty of Law of the Lomonosov Moscow State University, Moscow 